\title{
CATEGORIAS DE BASE DE FUTEBOL: TERRITÓRIO DE TRABALHO INFANTIL
}

\author{
Honor de Almeida Neto ${ }^{1}$ \\ Everton Rodrigo Santos ${ }^{2}$
}

Introdução

O futebol é o esporte mais assistido no mundo inteiro. De enorme apelo popular, esporte do terceiro milênio, da globalização e da sociedade em rede ${ }^{3}$, que movimenta uma indústria econômica multifacetada, além de envolver e mobilizar emocionalmente inúmeras pessoas e nações.É nesse cenário que são formados, desde muito cedo, os jogadores para os clubes de futebol. Este estudo analisa alguns pontos que distinguem o processo de produção de atletas de alto desempenho e que incidem diretamente na qualidade da produção da infância das crianças envolvidas. Essa trajetória, com vistas à profissionalização, desde o ingresso nas escolinhas de futebol “amador”, é muito árdua, extenuante, extremamente competitiva e requer inúmeras privações de crianças, adolescentes e de seus familiares.Trata-se de um processo de formação que, por suas características, incide diretamente na qualidade da produção da infância ${ }^{4} e$ da adolescência desses jovens.O universo que cerca a profissionalização no esporte é um território de adultos, que fomenta e impulsiona inúmeras práticas associadas ao que se denominou de trabalho infantil ${ }^{5}$.

A produção teórica em torno do tema da infância e dos riscos do trabalho precoce remete a determinados aspectos que encontramos sem muito esforço no mundo do futebol e, particularmente, nesse território de formação e de produção de infância

1 Universidade Luterana do Brasil, ULBRA, Brasil.

2 Universidade FEEVALE, Brasil.

4 Uma rede é um conjunto de nós interconectados. A formação de redes é uma prática humana muito antiga, mas as redes ganharam vida nova em nosso tempo, transformando-se em redes de informação energizadas pela Internet [...] (Castells, 2003: 7).

5 “A infância é análoga ao aprendizado da linguagem. Tem uma base biológica, mas não pode se concretizar a menos que um ambiente social a ative e a alimente, se as necessidades da cultura não a exigem, então a infância continua muda (POSTMAN, 1999: 158).

6 É toda e qualquer atividade útil, executada por crianças com menos de 16 anos, com certa regularidade (média de 15 horas por semana), com salário ou remuneração e ainda que envolva situações de risco tanto no cotidiano do trabalho como também para uma formação escolar regular (ALMEIDA NETO, 2003: 16).

Iluminuras, Porto Alegre, v. 19, n. 47, p. 94-118, dec, 2018. 
que são as categorias de base de clubes de futebol profissional. Aspectos como: os prejuízos físicos, tendo em vista estar a criança em processo primário de formação óssea e muscular; a pressão excessiva que gera estresse e, via de regra, distingue adultos de crianças em fase de construção de sua personalidade e de sua inteligência emocional; e a inversão de papéis entre o adulto e a criança, tendo em vista que o mundo do trabalho é o mundo por natureza do adulto. Por fim, a relação entre trabalho infantil e evasão escolar, fenômeno também muito presente no universo de formação de crianças das categorias de base de futebol.

Os riscos de lesões e a enorme e crescente competitividade por um espaço nos clubes, impulsionado pela globalização dos mercados, agora em rede, nos leva a crer que são realmente vencedores aqueles que chegam um dia a vestir a camisa de um clube profissional e, mais ainda, os que conseguem vencer nesse metié em um clube grande. Estima-se que em torno de $1 \%{ }^{6}$ apenas consiga alcançar a profissionalização.

Este artigo discute o processo de formação de crianças e adolescentes nas categorias de base de futebol, mais especificamente no Sport Club Internacional, lócus da pesquisa que vem sendo realizada desde o ano de 2008. É importante ressaltar que o estudo analisa a realidade de um clube de ponta, cujo trabalho de base é referência nacional e internacional, e que se constitui por isso em um caso exemplar de sucesso e cuidado na formação e no lançamento de jovens talentos do futebol. Embora seja uma exceção no comparativo com os demais clubes formadores do país, carrega características inerentes a esse universo altamente competitivo e rentável que é o futebol profissional. Características que guardam estreita relação com o contexto de trabalho infantil, embora estejamos falando aqui de uma categoria peculiar de trabalho infantil e que exige, portanto, uma sofisticação no olhar do pesquisador, pois o universo do futebol está associado a um desejo de consumo tipicamente juvenil: saúde, fama, beleza estética, sucesso, mídia e riqueza. Esse ideário que cerca o mundo do futebol, e que se aplica evidentemente a outros esportes de alto desempenho, movimenta e preenche o imaginário de milhares de crianças, adolescentes e seus familiares no país e no mundo.

\section{Metodologia}

7 Fonte: http://www.observatoriodainfancia.com.br/. Exploração do trabalho infantil no futebol, $18 / 12 / 2007$. 
Os dados aqui apresentados são produto de um estudo iniciado em novembro de 2008 junto a uma amostra significativa da população de atletas e profissionais das categorias de base do Sport Club Internacional. Trata-se de um estudo de casos. Nesta primeira fase da coleta de dados, foram aplicados questionários junto às crianças e adolescentes atletas do clube e seus familiares, bem como a todo o corpo técnico do clube (treinadores, coordenadores técnicos, fisioterapeutas, preparadores físicos, psicólogos). Para isso, foram utilizadas as próprias dependências do clube, através de uma parceria com a equipe de Assistentes Sociais ${ }^{7}$ que disponibilizaram os cadastros dos atletas e cederam suas salas para a realização das entrevistas. As entrevistas foram previamente agendadas e autorizadas através do preenchimento de termos de consentimentos por parte dos pais e responsáveis, referendado pelo Comitê de Ética da Universidade Luterana do Brasil. Foram todas gravadas e transcritas e os dados tabulados e tematizados. Os dados coletados referem-se a uma amostra de 42 crianças (nascidas em 97 e 98) e 41 pais/responsáveis pelos respectivos atletas. Muito embora nossa pesquisa seja um estudo de caso de cunho quanti-qualitativo, cumpre assinalar que foram pesquisados $70 \%$ da população em tela. A investigação responde ao seguinte problema de pesquisa: Como vem se constituindo o processo de formação de crianças nascidas entre 1998 e 1997 das categorias de base do Sport Club Internacional em Porto Alegre?

Novas dinâmicas do futebol: a infância em cheque

As relações humanas e sociais na sociedade em rede são construídas sob novas bases. Os fundamentos da sociedade contemporânea estão associados a determinados aspectos que a distinguem como velocidade, visibilidade, diversidade e compartilhamento, que constituem seus principais fundamentos. As mudanças nas dimensões de espaço (hoje desterritorializado) e de tempo (atemporal) rompem com características antes presentes no campo esportivo, rupturando-o. Complexifica-se a dinâmica do campo esportivo construído hoje sobre nova episteme: a episteme da Rede Dinâmica que instaura um novo padrão de relações. Impõe-se, nesse sentido, que

8 Assistentes Sociais Bernardette Mole Richard e Patrícia Bom Vasconcellos na época à frente do departamento profissional e amador respectivamente. 
lancemos um olhar diferenciado sobre esse fenômeno, atualizando-o, pois o futebol hoje, como aliás todos os fenômenos sociais, constrói-se em rede.

Na sociedade da Terceira Revolução Industrial, a metáfora da criança como uma planta a ser cuidada, regada e que exige, portanto, proteção especial, é tensionada pela metáfora do Supergaroto. Uma noção errônea sobre a capacidade e as condições das crianças em resistirem a toda e qualquer pressão (Elkind, 2004). No caso específico dos esportes de alto desempenho, esse tensionamento está associado,por exemplo, à concorrência interna e externa por espaço dentro do grupo de jogadores e pela pressão por resultados. Pressão que antes era amenizada nas categorias de base por seu caráter até certo ponto amador e de "fabricação" de atletas para a categoria profissional e que hoje aumentou e é inerente a esse processo de formação ${ }^{8}$.

Aumenta a competitividade que agora se dá em nível global, como demonstra a tabela a seguir:

Tabela 01- Local de nascimento

\begin{tabular}{|l|l|l|}
\hline RESPOSTAS & $\mathbf{N}^{\mathbf{0}}$ RESPOSTAS & \% \\
\hline Porto Alegre (RS) & 16 & 38.1 \\
\hline Alvorada (RS) & 2 & 4.8 \\
\hline Pelotas (RS) & 2 & 4.8 \\
\hline São Paulo (SP) & 2 & 4.8 \\
\hline Blumenau (SC) & 2 & 4.8 \\
\hline Santa Cruz do Sul (RS) & 1 & 2.4 \\
\hline Viamão (RS) & 1 & 2.4 \\
\hline Gravataí (RS) & 1 & 2.4 \\
\hline Nova Prata (RS) & 1 & 2.4 \\
\hline Montenegro (RS) & 1 & 2.4 \\
\hline Santiago (RS) & 1 & 2.4 \\
\hline Esteio (RS) & 1 & 2.4 \\
\hline Santana do Livramento (RS) & 1 & 2.4 \\
\hline Encantado (RS) & 1 & 2.4 \\
\hline Igrejinha (RS) & 1 & 2.4 \\
\hline Florianópolis (SC) & 1 & 2.4 \\
\hline Maravilha (SC) & 1 & 2.4 \\
\hline Xaxim (SC) & 1 & 2.4 \\
\hline Maringá (PR) & 1 & 2.4 \\
\hline Cascavel (PR) & 1 & 2.4 \\
\hline Pato Branco (PR) & 1 & 2.4 \\
\hline Porto Seguro (BA) & 1 & 2.4 \\
\hline Bogotá (CO) & 1 & 2.4 \\
\hline
\end{tabular}

9 "Formação é a ação pela qual algo se forma, é produzido; é a ação de formar, de organizar, de instruir, de educar e seu resultado. E formado é aquele que recebeu uma certa forma; que foi habituado conforme tal forma ou tal feitio" (Desaulniers, 1997: 191). 


\begin{tabular}{|l|l|l|}
\hline Total & 42 & 100 \\
\hline
\end{tabular}

Fonte: Entrevistas crianças/dados primários [grifo meu]

Embora haja uma constante rotatividade $^{9}$ de atletas, sobretudo de uma temporada (um ano) para outra, e uma crescente oferta ${ }^{10}$ de novos atletas,não há ampliação de espaço, ou seja, há sempre o limite de 30 a 35 vagas por categoria (determinada pelo ano do nascimento). As falas a seguir de alguns pais refletem essa incerteza e os riscos de dispensas,frente a uma concorrência que hoje é global e não mais restrita ao espaço local,

- ...a gente sempre fala pra ele, a gente nunca sabe o dia de amanhã, tem muitos passos pela frente... ele sabe que todo dia tá vindo guri de fora, tá vindo outros meninos que jogam bem, então a gente "por enquanto tu tá ${ }^{11}$ te mantendo, a gente não sabe depois” e ele aceita numa boa, ele sabe que é assim mesmo. (mãe de atleta).

-Eu vejo muita gente aqui no Inter mesmo, que desloca da Bahia, eu acho um absurdo fazê isso, ainda mais com criança...aí vem competi com os outros aqui. Aí dizem que porque lá não tem categoria de base, tem sim, mas sei lá por que que vem...” (mãe de atleta).[grifo meu]

- Faz um mês apenas que ele está aqui no Inter...estamos longe desse glamour...a cada treino ele tem que treinar bem. Sempre está chegando meninos novos até porque a gente investe...ele vem de TOPIC e tem que pagar...já que moramos em Novo Hamburgo...Ele não pode vir aqui pra brincar, ele tem que ter seriedade...Brincar ele brinca em casa, aqui é sério...” (mãe de atleta). [grifo meu]

A expectativa pela realização do sonho da profissionalização e o retorno de todo o investimento familiar em tempo e em dinheiro é tanto das crianças quanto dos pais, como podemos demonstrar através das tabelas a seguir:

Tabela 02- Desejas te tornar jogador profissional?

\begin{tabular}{|c|c|c|}
\hline RESPOSTAS & $\mathbf{N}^{\mathbf{0}}$ RESPOSTAS & FREQUÊNCIA \% \\
\hline Sim & 41 & 97.6 \\
\hline Não sei ainda & 01 & 2.4 \\
\hline
\end{tabular}

10 Em torno de 30\% dos atletas não ficam no clube de um ano para outro, a rotatividade é muito grande e a competitividade crescente. A trajetória nas categorias de base começa em torno de9 a 10 anos. Significa que a criança precisa sobreviver no clube pelo menos em torno de 8 a 10 anos quando, então, poderá ingressar no cobiçado estágio de profissionalização.

11 Segundo um dos avaliadores técnicos do Sport Club Internacional, somente no ano de 2008, em torno de 11 mil jovens atletas foram avaliados pelo Internacional e, desse número, apenas 60 foram aprovados em todos os testes e se tornaram atletas do Internacional.

12 Os depoimentos estão transcritos na fala original dos entrevistados como forma de aproximar o leitor à realidade e tornar mais fiel possível a transcrição. 


\begin{tabular}{|c|c|c|}
\hline Não & 00 & 00 \\
\hline TOTAL & 42 & 100 \\
\hline
\end{tabular}

Fonte: Entrevistas crianças/dados primários

Como apontamos anteriormente, trata-se de uma atividade peculiar de trabalho infantil que exige uma sofisticação maior na análise, sobretudo se compararmos com outras modalidades de trabalho infantil, distante do imaginário associado ao jogador de futebol e ao esporte. Ser jogador profissional é o desejo de inúmeras crianças mundo a fora e, particularmente, no Brasil. Os depoimentos a seguir de pais de atletas corroboram essa perspectiva:

É uma nova vida, uma nova fase, a gente tá aprendendo tudo de novo, a conviver com um grupo novo, de pessoas novas... a gente aceitou, quando ele veio fazer o teste, que pai e mãe iam ter que se mudar por causa dele... a gente tá num clube de estrutura grande, as vezes não tem o mesmo contato que a gente tinha lá, mas pra ele, a vivência, almoçá no refeitório, tudo é muito bom. (mãe de atleta) [grifo meu]

O que menos me agrada é ele ter que vim sozinho, isso aí me corta o coração. Tem tanta gente ruim nesse mundo, eu que vejo ele sair de dentro da minha casa, sabendo que ele tem 11 anos e só tem tamanho, pelo amor de Deus. (mãe de atleta) [grifo meu]

A tabela a seguir reforça a expectativa que é depositada na criança pelos pais, que aumenta a pressão pelo sucesso do menino neste projeto:

Tabela03- Expectativa quanto ao futuro do menino no futebol profissional?

\begin{tabular}{|c|c|c|}
\hline RESPOSTAS* & N $^{\mathbf{0}}$ RESPOSTAS & $\mathbf{\%}$ \\
\hline Que seja um bom profissional & 11 & 18 \\
\hline Que se realize seu sonho & 08 & 13.1 \\
\hline Melhores possíveis & 06 & 9.8 \\
\hline Que seja uma grande pessoa/cidadão & 04 & 6.5 \\
\hline Que vença como jogador & 04 & 6.5 \\
\hline Não tenho grandes expectativas & 04 & 6.5 \\
\hline Que seja um grande jogador (atleta) & 03 & 4.9 \\
\hline Hoje é uma diversão & 03 & 4.9 \\
\hline Priorizamos o estudo & 03 & 4.9 \\
\hline Que não decepcione e vá longe na carreira & 02 & 3.3 \\
\hline Que seja feliz & 02 & 3.3 \\
\hline Ele está aqui porque ele gosta & 02 & 3.3 \\
\hline Estar sempre do lado dele, incentivar & 02 & 3.3 \\
\hline O futuro dele vem de berço o guri é bom de bola & 01 & 1.6 \\
\hline Que não se decepcione no futuro & 01 & 1.6 \\
\hline Que tenha boas lembranças desse momento & 01 & 1.6 \\
\hline
\end{tabular}




\begin{tabular}{|c|c|c|}
\hline Depende da oportunidade que tiver & 01 & 1.6 \\
\hline Não sabe, não respondeu & 03 & 4.9 \\
\hline TOTAL & 61 & 100 \\
\hline
\end{tabular}

* Alguns pais deram mais que uma resposta

Fonte: Entrevistas pais/responsáveis/dados primários [grifo meu]

Reforçamos que o investimento e o sonho são de toda a família e, sobretudo, do pai, fato que não ocorre por acaso:

Tabela 04- Quem mais te incentiva a ser jogador de futebol?

\begin{tabular}{|c|c|c|}
\hline RESPOSTAS & $\mathbf{N}^{\mathbf{0}}$ RESPOSTAS & FREQUÊNCIA \% \\
\hline Pai & 17 & 40.4 \\
\hline Pai e mãe & 06 & 14.3 \\
\hline Pai, mãe e irmãos & 07 & 16.3 \\
\hline Mãe & 03 & 7.1 \\
\hline Toda família & 03 & 7.1 \\
\hline Avós e dindo & 02 & 4.8 \\
\hline Pai e irmãos & 01 & 2.4 \\
\hline Pai e avô & 01 & 2.4 \\
\hline Mãe e avós & 01 & 2.4 \\
\hline Ninguém & 01 & 2.4 \\
\hline TOTAL & 42 & 100 \\
\hline
\end{tabular}

Fonte: Entrevistas crianças/dados primários

Aqui é possível aferir que há muitos aspirantes a profissionais filhos de exjogadores e/ou de jogadores que não venceram no universo do futebol, ou por lesões ou por incapacidade técnica, sorte, e outros inúmeros fatores e acidentes de percurso. Há aqui, também, em certa medida, uma projeção do sonho e do desejo dos pais na vida dos filhos. Isso explica porque o maior incentivador é sempre o pai, com mais de $80 \%$ dos casos avaliados. Observa-se também uma inversão de papéis na relação entre crianças e adultos que explica o investimento feito, sobretudo pelos familiares. Quando indagados sobre o motivo do investimento nessa atividade, fica claro que não estamos falando de atividades lúdicas, mas de trabalho com vistas a aferir lucro,como demonstram os dados a seguir:

Tabela 05- Acredita que está investindo no futuro dele e da família mantendo-o no clube?

\begin{tabular}{|l|c|c|}
\hline RESPOSTAS* & $\mathbf{N}^{\mathbf{0}}$ RESPOSTAS & $\%$ \\
\hline Sim & 08 & 42.1 \\
\hline Sim, mas somente no futuro dele & 07 & 36.8 \\
\hline Depende & 02 & 10.5 \\
\hline Não & 02 & 10.5 \\
\hline TOTAL & 19 & 99.9 \\
\hline
\end{tabular}


Fonte: Entrevistas pais/responsáveis/dados primários

Os depoimentos abaixo corroboram essa ideia:

Sim, é o sonho de todos né, temos que investi, gastá, pra vim mais tarde, é o futuro dele e ele também um dia vai meajudá também né, acho que isso é um trabalho...” (pai de atleta) [grifo meu]

No futuro dele sim, no da família não sei, só se der algum resultado. (pai de atleta) [grifo meu]

Não tenho dúvida nenhuma, to investindo sim, na educação dele. (pai de atleta)

A tabela abaixo reforça a noção de que, mais do que uma atividade esportiva, trata-se de um investimento, com expectativas de retorno.

Tabela 06- Conta com sua ajuda financeira no futuro?

\begin{tabular}{|l|c|l|}
\hline RESPOSTAS* & $\mathbf{N}^{\mathbf{0}}$ RESPOSTAS & \% \\
\hline Sim & 05 & 26.3 \\
\hline Depende & 1122 & 57.9 \\
\hline Não & 0306 & 15.8 \\
\hline TOTAL & 19 & 100 \\
\hline
\end{tabular}

Fonte: Entrevistas pais/responsáveis/dados primários

Os relatos abaixo ilustram essa relação:

Eu quero estar aqui pra ver ele vencer, é importante que ele vença, que ele possa me ajudá mais tarde também né. (pai de atleta) [grifo meu]

No momento não, de repente no futuro eles quiseram ajudar, mas por enquanto não, deixa pra eles. (mãe de atleta)

Eu vejo ele falá isso...mas não, em brincadeira ele fala que vai me dar uma casa grande... a gente nem sabe como vai ser o futuro né, mas o maior erro pode estar aí, tu planejá uma coisa que tu não sabe se vai acontece ou não né. (pai de atleta)

Quando ele ganhar muito dinheiro sim, mas por enquanto sai do nosso bolso. (pai de atleta) [grifo meu]

A tabela a seguir demonstra a visão das crianças sobre a responsabilidade que julgam ter de retribuir o investimento familiar feito em sua futura "carreira”:

Tabela 07- Acha importante as crianças ajudarem os pais financeiramente?

\begin{tabular}{|c|c|c|}
\hline RESPOSTAS & $\mathbf{N}^{\text {0 }}$ RESPOSTAS & FREQUÊNCIA \% \\
\hline Sim & 38 & 90.4 \\
\hline Não & 04 & 9.5 \\
\hline
\end{tabular}


Trata-se realmente de um investimento familiar, em dinheiro, pois há custos de deslocamento e compra de equipamento e, sobretudo, em tempo. É uma relação mercantil e que envolve a figura dos empresários. Esses negociam diretamente com os pais o vínculo com os atletas. Essa negociação envolve, desde a oferta de subempregos para os pais na cidade, como atrativo para que se desloquem de suas cidades natais, até valores em dinheiro. Por vezes, a negociação envolve ou o pagamento de mensalidade em uma escola particular de melhor qualidade na capital ou a matrícula em escola pública com contrapartida em dinheiro aos pais. Chama a atenção a dinâmica de alguns empresários que disponibilizam moradia temporária para as crianças em que há uma rotatividade dos responsáveis, como ilustra a fala a seguir:

É, a gente trabalha muito aqui com eles, principalmente os que estão no alojamento, que são atletas da nossa responsabilidade, porque nós temos várias situações, tem atletas que ficam em pensão, tem atletas que ficam em casas compartilhadas que tem um adulto, pai ou responsável de alguém, comandando, e tem os meninos do alojamento e os que vem e voltam ao clube, os que vão pra casa e vem treinar no outro dia. Para nós o que a gente dá mais ênfase, são os que estão sob a nossa responsabilidade, que estão aqui no alojamento.

(Psicóloga do Clube) [grifo meu]

Assim, por exemplo, a mãe de uma das crianças reside uma semana e reveza com as demais mães ou responsáveis, “cuidando” dos demais. O depoimento a seguir reflete essa dinâmica:

Tô sendo bem sincero, a gente já conta agora, porque o suporte todo, quando eu tô desempregado, quem mantém é ele, pelo Inter e pelo empresário, então... se agora nós já contamos, imagina lá na frente. Claro, eu não gostaria, queria ter a minha, só que, eu sou treinador de futsal, e o futsal é muito verbal, ele é muito, o futebol é muito sujo. O futsal ele não tem contrato, ele não tem carteira assinada. (pai de atleta) [grifo meu]

Configura-se uma espécie de estágio que visa à profissionalização para um mercado extremamente competitivo em que não há abertura de novos postos de trabalho para os "pé-de-obra" ${ }^{12}$, pois

13 Trata-se do conceito trabalhado por Damo (2007), em analogia ao conceito de mão-de-obra. 
Há, em contrapartida, possibilidades de emprego no mercado internacional, mas boa parte dessas oportunidades são em países futebolisticamente periféricos, ou em clubes de segunda e terceira divisões de mercados mais glamorosos...Mas, não é com essa expectativa que os meninos entram para os centros de formação. O projeto deles é um sonho, e como tal nada modesto: a seleção brasileira, os grandes clubes brasileiros e europeus - o Inter, o Olympique Marseille (OM)...etc.(Damo, 2007). [grifo meu]

O processo de formação de atletas de alto desempenho exige, como vimos, privações e, desde cedo, jovens aspirantes a profissionais têm que adaptar sua rotina a treinos, viagens e demais demandas a um atleta,pois “...essa realidade afasta-se das atividades de garotos: entretenimento, amizades, escolarização...os garotos se entregam à incorporação dos capitais futebolísticos” (Damo: 24). O caráter estritamente formativo, que era o principal propósito das categorias de base, deu lugar hoje à crescente mercantilização desse espaço, onde, hoje, os atletas são comercializados e rendem dinheiro ao clube, desde muito cedo. Nas palavras de Damo:

...atrás da trama simbólica que faz parte do poder de sedução da profissão de jogador, existe um processo altamente competitivo, exigindo aproximadamente 5.000 horas de investimentos num período de dez anos, e que envolvem rotinas cansativas e monótonas...Trata-se de uma tecnologia aplicada diretamente no corpo...e visa converter jovens talentosos em profissionais capazes de mostrar um desempenho à altura das exigências dos torcedores.....(Damo, 2007: 18) [grifo meu]

Esse novo cenário vem pressionando cada vez mais a infância ${ }^{13}$ dessas crianças e adolescentes, adultizando-as ${ }^{14}$ precocemente.Chama a atenção que quase $78 \%$ das crianças já treinaram em outro clube antes de chegarem no Inter, mesmo que estejamos falando de crianças que na época da coleta de dados tinham entre 9 e 11 anos de idade no máximo. Há em torno de $46 \%$ de atletas que estão no clube há mais de 4 (quatro) anos, 30\% está no Inter desde os 7 anos de idade aproximadamente e quase a metade desde os 8 anos de idade alimentam o seu sonho. Esse dado é relevante, se analisarmos os possíveis efeitos de dispensas de atletas na transição das categorias ${ }^{15}$ frente ao

14 “A infância é análoga ao aprendizado da linguagem. Tem uma base biológica, mas não pode se concretizar a menos que um ambiente social a ative e a alimente...se as necessidades da cultura não a exigem, então a infância continua muda (POSTMAN, 1999: 158).

15 Quanto ao conceito de adultização: “Hoje o trabalho infantil pode ser traduzido por adultização, a adultização de crianças não é uma novidade na história humana, ela sempre existiu. A questão central é que ela não atinge mais somente a criança "pobre”, tem uma amplitude muito maior, é uma "epidemia” que assola todas as camadas sociais” (ALMEIDA NETO, 2006: 118). 
investimento tanto dos pais quanto das crianças, de tempo e dinheiro na busca em se tornar jogador profissional. Quanto ao tempo em que estão treinando no clube, veja a tabela a seguir:

Tabela 8- Tempo em que está no Inter

\begin{tabular}{|c|c|c|}
\hline RESPOSTAS & $\mathbf{N}^{\mathbf{0}}$ RESPOSTAS & $\mathbf{\%}$ \\
\hline Até 6 meses & 05 & 11.9 \\
\hline De 7 a 10 meses & 09 & 21.9 \\
\hline 1 ano & 06 & 14 \\
\hline 1 ano e 6 meses & 03 & 7 \\
\hline 2 anos & 06 & 14 \\
\hline 3 anos & 09 & 21.9 \\
\hline 4 anos & 04 & 9.7 \\
\hline TOTAL & 42 & 100 \\
\hline
\end{tabular}

Fonte: Entrevistas crianças/dados primários

Como apontamos anteriormente, o risco de dispensas e a instabilidade são constantes, conforme ilustram alguns depoimentos a seguir de pais de atletas:

Eu acho que se um dia o Inter não quiser ele mais aqui, ele vai pra outro clube né, prátentá porque o que ele quer mesmo é ser jogador.., nunca conversei se ele gostaria de ser outra coisa assim. (pai de atleta)

Eu digo que cada treino é um treino e eles sempre tem que esperá o pior, e ele que é titular pode cair pro banco, pode ser dispensado, e o Inter não é o único clube que tem né, eu sempre digo pra eles, que carreira de futebol não é assim né. (pai de atleta)

Ele entrou na escolinha pra jogar futebol, pra brincá, fazê o que ele gosta, ele continua fazendo o que ele gosta, mas de outra forma, com aquela cobrança, mas a gente sempre fala pra ele, a gente nunca sabe o dia de amanhã, tem muitos passos pela frente... ele sabe que todo dia tá vindo guri de fora, tá vindo outros meninos que jogam bem, e ele aceita numa boa, ele sabe que é assim mesmo. (pai de atleta) [grifo meu]

No contato com as comissões técnicas, fica claro que a questão central é, além da capacidade de jogar bem futebol, a capacidade de resistir. Resistir à pressão por resultados e a competitividade interna crescente e resistir, sobretudo, à carga de trabalho física e às lesões.

16 Em torno de 30\% dos atletas não ficam no clube de um ano para outro, a rotatividade é muito grande e a competitividade crescente. 
Então eles queimam muitas etapas e a gente sempre pontua pra eles, que a gente sabe que vcs são muito cobrados, que vcs tão sempre sob pressão, que vcs vivem uma competição diária, que isso que nem todos vão ser atletas profissionais. E ao mesmo tempo que vc as vezes já tem uma equipe, chega outra pessoa de fora pra fazer um teste e sobe antes de vc, e ai fica toda uma expectativa, então acho que a gente tem que trabalhar muito a cabecinha deles pq eles queimam uma etapa, né, de poder aproveitar. (Psicóloga do clube)

O contexto de formação de atletas exige sacrifícios e antecipação de etapas, assim são forjados os futuros profissionais do futebol.

Pressão, futebol e infância

As inúmeras formas de pressão que recaem prematuramente sobre crianças e adolescentes no mundo do futebol invertem a lógica legal de proteção integral associada ao ECA (Estatuto da Criança e do Adolescente) e suscitam a seguinte questão: "Qual será a melhor forma de integrar a prática do desporto e os seus efeitos benéficos na formação e desenvolvimento do organismo infantil e juvenil: para isso, a criança não deve dedicar-se à competição erigida em dogma, mas a competição deve, pelo contrário, estar adaptada à infância e às suas características específicas” (PERSONNE, 2001).

Nas palavras dos treinadores, o grande dilema que assola os clubes de ponta no Brasil é se devem “formar ganhando, ou ganhar formando”, porém, o que se observa é que a competição e a exigência por vitórias estão na gênese deste processo. $O$ habitus ${ }^{16}$ do jogador de futebol é forjado, portanto, desde tenra idade, em todo o tempo em que as crianças estão no clube, alimentando e fomentando seu sonho de se profissionalizar. A tabela a seguir ilustra a forma como enfrentam a pressão:

Tabela 09- Como reage à pressão?

\begin{tabular}{l|l|l|} 
RESPOSTAS & $\mathbf{N}^{\circ}$ RESPOSTAS & FREQUÊNCIA \% \\
\hline
\end{tabular}

17 Quanto ao conceito de habitus: “Os ‘sujeitos’ são, de fato, agentes que atuam e que sabem, dotados de um senso prático, de um sistema adquirido de preferências, de princípios de visão e de divisão (o que comumente chamamos de gosto), de estruturas cognitivas duradouras (que são essencialmente produto da incorporação de estruturas objetivas e de esquemas de ação que orientam a percepção da situação e a resposta adequada). O habitusé essa espécie de senso prático do que se deve fazer em dada situação...” (BOURDIEU, 1997: 42). 


\begin{tabular}{|c|c|c|}
\hline Normal / Fico tranquilo & 23 & 54.8 \\
\hline Fica nervoso & 08 & 19 \\
\hline Procura melhorar cada vez mais & 05 & 11.9 \\
\hline Normal mas às vezes chateia & 02 & 4.8 \\
\hline Não tem pressão & 02 & 4.8 \\
\hline Fica estressado / Briga em casa & 01 & 2.4 \\
\hline Procura esquecer & 01 & 2.4 \\
\hline TOTAL & 42 & 100.1 \\
\hline
\end{tabular}

Fonte: Entrevistas crianças/dados primários

Há que se analisar o preço cobrado pelo risco inerente e quase inevitável do fracasso, da decepção, da derrota e da frustração familiar e, sobretudo, individual, que recai precocemente sobre esses agentes em processo de formação do corpo e de afirmação de sua personalidade:

São adolescentes, boa parte vinda de grupos populares, investidos por representações de masculinidade que os fazem propensos aos desafios que o futebol exige, dentro e fora de campo, especialmente no tocante a uma ascese ${ }^{17}$ mundana calcada na prática corporal e no esforço físico continuado. A carreira começa efetivamente, e por vezes termina, num centro de formação.(Damo, 2007: 24).

Vê-se que, também nesse contexto do desporto, a infância vem sendo tensionada, cada vez mais cedo, a deparar-se com questões para as quais ainda não tem estrutura cognitiva e, sobretudo, emocional para resolver, como por exemplo a pressão por resultados. Essa pressão, que antes era amenizada nas categorias de base por seu caráter até certo ponto amador e de fabricação de atletas para a categoria profissional, hoje aumentou. Até porque é crescente a mobilidade do jogador de futebol desde tenra idade, assim como o número de negociações com o mercado nacional e sobretudo internacional:

Eles sofrem muita pressão, a grande maioria vem de famílias pobres, sem estrutura financeira, os pais pegando os filhos praticamente como uma mercadoria pra transformar a família, pra trazer dinheiro pra família. Muitos atletas, às vezes, com o pouco dinheiro que ganham de bolsa eles sustentam a família. Então, claro que fica a cobrança, eles têm muito medo de perder esse espaço e não poder mais ajudar e a família também cobra, né. Tem vários casos de atletas que trabalham ${ }^{18}$ e que não pegam um centavo do seu dinheiro, que a família é que usufrui. Então tem várias situações até de inversão de valores, de colocar a responsabilidade num menino de 14, 15 anos pra ser o sustento de uma família. E todo o sonho dessa família, fica

18 Disciplinas austeras e de autocontrole.

19 Ela usa esse termo para se referir aos atletas que recebem uma bolsa, admitindo que a atuação nas categorias de base se configura como trabalho remunerado. 
voltado... então é muito, é um peso muito grande, porque além dele querer ser profissional, ele tem toda essa situação de outras pessoas dependendo dele.(Psicóloga do clube) [grifo meu]

O abreviamento da infância tem reflexos no comportamento do atleta no futuro quando adulto:

A gente vê os meninos de 17, 18 anos como crianças grandes. Eles não têm maturidade, muitas vezes, pra responsabilidade que a profissão exige. Eles queimam muitas etapas, porque desde os 10, 11 anos, tu dentro de um esporte que requer disciplina, que requer regras, que requer que tu tenhas aptidão técnica, tática (Psicóloga do clube).

Ainda quanto à pressão por desempenho e resultados:

A cobrança é muito grande, e aí eles terminam esquecendo outras coisas que faziam parte do universo deles, que é a parte social, que é a parte escolar, pra ficar focado só no futebol e muitas vezes eles quebram a cara, porque desse universo que estão aqui, 5\% pode se tornar jogador profissional”. (Psicóloga do clube)

Efetivamente, a criança e o adolescente atletas hoje constituem-se, já nas categorias de base e, portanto, desde tenra idade, em mercadoria dos clubes de futebol, dos empresários e dos próprios pais. Essa relação tipicamente mercantil adultiza precocemente as crianças, abreviando o período da infância e da adolescência, fato agravado pela globalização dos mercados e o encurtamento das distâncias associados ao advento das novas tecnologias de informação e comunicação (NTIC). O depoimento a seguir ilustra também essa nova dinâmica:

Essa mudança que aconteceu no futebol ela foi muito sutil, antigamente o atleta era vendido muito mais tarde, ele tinha tempo, então ele convivia ainda com a sociedade, hoje em dia não dá tempo, então ele sai da escola primária logo com 10 anos e quando fazem 15 já tão com assédio do clube, dos empresários, as pessoas já esperando muito ou uma performance dele dentro do campo como se eles fossem adultos maduros. (Auxiliar Técnico)

Na esteira dessa discussão, os prejuízos físicos sempre foram apontados, pela bibliografia especializada no tema, como um risco associado ao trabalho precoce, em função da exigência inadequada de esforço físico em um período de formação ósseo muscular.Claro, pensamos imediatamente no trabalho infantil cujas dinâmicas envolvem condições muitíssimo mais precárias como carregar peso, ficar em pé, dormir pouco, lidar com produtos tóxicos, dentre outras. Claro que aqui estamos falando de 
prática esportiva, porém voltada ao alto desempenho, voltado à competição e que pouco se assemelha, por exemplo, a atividades lúdicas e de lazer.

Há toda uma produção teórica, aparentemente ignorada pela realidade dos clubes de futebol sobre os riscos à saúde física de crianças e adolescentes. Nesse sentido, o francês Jacques Personne (2001) fez uma exposição completa dos danos causados pelo treino intensivo precoce e apontou que “o desporto pode mostrar-se a melhor ou a pior das coisas, pois, se praticado em excesso e sem método, pode ser extremamente prejudicial ao organismo, causando-lhe danos as vezes para toda a vida das crianças” (Personne, 2001). É preciso levar em conta os efeitos e riscos do excesso de carga de trabalho físico em crianças, pois “as estruturas são, nesta idade, de uma particular fragilidade aos pesos mecânicos. Isso resulta da imaturidade que os torna muito sensíveis ao excesso de treino e aos micro-traumatismos” (Personne, 2001: 12).Essa discussão é extremamente relevante quando nos deparamos com esse cenário “selvagem” de garimpo de jovens atletas, jovens craques ou aspirantes a craques, fenômenos potenciais e os interesses de clubes, federações, pais e ávidos “empresários”:

Não será criminoso aceitar o risco de destruir a saúde de inumeráveis crianças e adolescentes para descobrir o indivíduo super cujo organismo se demonstrará, aliás, profunda e definitivamente arruinado depois de alguns anos de procura do melhor resultado a todo o preço, em condições muito ambíguas onde se misturam vaidade e glória, nacionalismo, política no mau sentido da palavra e algumas vezes considerações financeiras especialmente impuras? (Personne, 2001: 14).

O contexto que envolve o mundo do futebol é carregado de apelo emocional e desejo por vitória a todo custo, o que incide nessa relação entre clubes, empresários e atletas. Damo (Damo, 2001) denominou esse processo de clubismo, que envolve a paixão dos torcedores em primeiro lugar pelos clubes, territórios de compartilhamento de paixão. Vê-se o quão difícil é discutir direitos de crianças e adolescentes nesse contexto. Além disso, como apontado anteriormente, trata-se de uma atividade peculiar de trabalho infantil, até por tratar-se afinal de um esporte com todo o imaginário que o cerca. Justifica-se, assim, que pesquisemos o tema e que possamos agir no sentido de chamar atenção para esses riscos. As inúmeras formas de pressão que recaem prematuramente sobre crianças e adolescentes no mundo do futebol invertem a lógica legal de proteção integral associada ao Estatuto da Criança e do Adolescente (ECA) e o culto à competitividade excessiva cobra o preço daqueles que são os mais vulneráveis nesse processo, as crianças e os adolescentes. 
Inquietante evolução da alta competição. Quando ela se torna desenfreada, a procura da performance abandona necessariamente pelo caminho o respeito do indivíduo...Num tal quadro, as prioridades ligadas ao mundo tão particular da infância, esbatem-se. A população jovem não se define senão em talentos precoces, futuros performers, campeões em potência e medalháveis do amanhã (PERSONNE, 2001: 27).

Quanto aos prejuízos físicos associados a este esporte que é por natureza extremamente violento, veja as tabelas a seguir:

Tabela 10- Percebe cansaço físico ou mental no seu filho, por conta dessa prática no futebol?

\begin{tabular}{|l|c|c|}
\hline RESPOSTAS* & $\mathbf{N}^{\mathbf{0}}$ RESPOSTAS & \% \\
\hline Sim & 06 & 15.8 \\
\hline Às vezes & 14 & 36.8 \\
\hline Não & 18 & 47.4 \\
\hline TOTAL & 38 & 100 \\
\hline
\end{tabular}

Fonte: Entrevistas pais/responsáveis/dados primários

Os depoimentos a seguir ilustram o olhar dos responsáveis em relação aos riscos de lesões:

Não, eu sinto um cansaço nele de acordá cedo pra ir prá escola...pelo treino não até porque eles treinam pouco, o Grêmio treina 5 vez e eles 3...a gente calcula que aqui eles tão fazendo o trabalho certo e lá tá sendo forçado demais. (pai de atleta)

Físico né, ás vezes eles tem treino todas as tardes, se coincide que nem essa semana que ele tem prova todos os dias... e as coisas normais do dia a dia, pancadinha, joelho, tornozelo. (pai de atleta)

Quando questionados sobre a sua capacidade em suportar e conviver com dores, a tabela a seguir ilustra o fato de que, para vencer as etapas com vistas à profissionalização, é preciso aprender a conviver com a dor constantemente e resistir.

Tabela 11- Jogador de futebol tem que saber conviver com a dor?

\begin{tabular}{|c|c|c|}
\hline RESPOSTAS & $\mathbf{N}^{\mathbf{0}}$ RESPOSTAS & $\mathbf{\%}$ \\
\hline SIM & 37 & 88,1 \\
\hline NÃO & 5 & 11,9 \\
\hline TOTAL & 42 & 100 \\
\hline
\end{tabular}

Fonte: Entrevistas crianças/dados primários 
Saber jogar futebol é fundamental, é uma condição e via de regra todos que estão selecionados são habilitados, craques em potencial, porém resistir às pressões é que distingue os poucos “sobreviventes" nesse processo de seleção rigoroso com vistas à manutenção no grupo e no clube.

Tabela 12-Já treinou ou jogou com dor?

\begin{tabular}{|c|c|c|}
\hline RESPOSTAS & $\mathbf{N}^{\mathbf{0}}$ RESPOSTAS & FREQUÊNCIA \% \\
\hline SIM & 28 & 66.67 \\
\hline NÃO & 14 & 33.33 \\
\hline TOTAL & 42 & 100 \\
\hline
\end{tabular}

Fonte: Entrevistas crianças/dados primários

Mesmo em se tratando de crianças à época entre 10 e 11 anos, estas já carregavam um histórico de lesões:

Tabela 13-Já sofreu alguma lesão?

\begin{tabular}{|c|c|c|}
\hline RESPOSTAS & $\mathbf{N}^{\mathbf{0}}$ RESPOSTAS & FREQUÊNCIA \% \\
\hline SIM & 25 & 59,5 \\
\hline NÃO & 17 & 40,5 \\
\hline TOTAL & 42 & 100 \\
\hline
\end{tabular}

Fonte: Entrevistas crianças/dados primários

Como os dados apontam, a relação entre esporte e saúde não é linear em se tratando de esportes de alto desempenho. Porém, como referimos anteriormente, nosso caso exemplar que subsidia esse artigo envolve um clube de ponta com vasto investimento nas categorias de base e com um cuidado maior nesse sentido, como demonstram os depoimentos a seguir de um dos preparadores físicos do clube:

Bom, primeiro as sessões de treinamento elas são reguladas por tempo né, então a gente tem um tempo específico pra cada categoria, por exemplo o sub 10 não vai treinar 3 horas, como ele não vai fazer um treino físico, antes de um treino tático ou um coletivo que um guri do Junior já pode faze porque tem o corpo completamente desenvolvido, então tem, cada idade tem uma classificação do que eles podem, né, então se então houver um “over training” eles podem, sim, fazer movimentos repetitivos pra memoriza, nada que seja muito desgastante.

(Preparador físico)

Outro preparador reforça o cuidado do clube nesse sentido:

O nosso treinamento repetido e o específico ele tem um controle muito assíduo, muito árduo do nosso preparador físico, mas não deixa justamente, dar sobrecarga, movimentos repetitivos...dai a gente cuida bastante a criação de cada treinamento, pra justamente não entrar nessa situação de lesionar os garotos né, por isso que a gente tem profissional da fisiologia, de nutrição, toda essa assessoria para nós 
termos condições de no campo saber a carga de volume do treino, o tempo que a gente vai dá, pra não criá uma lesão. (Preparador Físico)

De qualquer forma, em se tratando de esporte voltado à competição e ao alto desempenho, a exigência sobre o corpo é muito grande e é agravada por tratarmos aqui de crianças em fase de formação.

Futebol e escola

Essa pesquisa analisou também a relação entre essa atividade e a frequência e valorização da educação formal, ou seja, o papel da escola na formação dessas crianças. Na bibliografia especializada sobre a temática do trabalho infantil, um dos aspectos associado aos riscos do trabalho precoce remete à desvalorização da escola por parte das crianças que trabalham e a evasão escolar. A formação de atletas de alto desempenho desafia a criança e os familiares a conciliar as duas atividades. Mensuramos, neste estudo, essa relação e apresentamos a seguir os resultados:

Tabela 14- Já trocou de colégio?

\begin{tabular}{|c|c|c|}
\hline RESPOSTAS & $\mathbf{N}^{\mathbf{0}}$ RESPOSTAS & FREQUÊNCIA \% \\
\hline Sim & 25 & 59.5 \\
\hline Não & 17 & 40.5 \\
\hline TOTAL & 42 & 100 \\
\hline
\end{tabular}

Fonte: Entrevistas crianças/dados primários

A crescente competitividade, hoje em escala global, faz com que inúmeras crianças e suas famílias se desloquem de suas cidades para a capital, afim de facilitar a logística que envolve a rotina de treinos, que ocorrem em média três vezes por semana, sendo os jogos e torneios geralmente realizados aos finais de semana. Quanto ao período de frequência à escola, a maior parte estuda pela manhã e treina três vezes por semana à tarde.

Tabela 15- Período em que frequenta a escola

\begin{tabular}{|c|c|c|}
\hline RESPOSTAS & $\mathbf{N}^{\mathbf{0}}$ RESPOSTAS & FREQUÊNCIA \% \\
\hline Manhã & 40 & 95.2 \\
\hline Tarde & 02 & 4.8 \\
\hline TOTAL & 42 & 100 \\
\hline
\end{tabular}

Fonte: Entrevistas crianças/dados primários 
Embora ainda neste estágio seja possível conciliar os treinos e a frequência à escola, a prioridade recai sempre sobre o futebol. Assim, se a criança tiver de escolher entre o treino da tarde e uma consulta ao dentista, por exemplo, sempre a prioridade é o futebol.

Há um mito de que crianças que não tenham um bom desempenho na escola não frequentam as competições, porém, é difícil imaginar que, neste contexto, futuros craques sejam alijados desse processo em função disso. Porém, como todos os mitos, este cumpre uma função e de alguma forma influencia positivamente a frequência e a preocupação com a escola.

Tabela 16- O Inter exige frequência e bom desempenho na escola?

\begin{tabular}{|c|c|c|}
\hline RESPOSTAS & $\mathbf{N}^{\mathbf{0}}$ RESPOSTAS & FREQUÊNCIA \% \\
\hline Sim & 27 & 64.3 \\
\hline Não & 12 & 28.6 \\
\hline Mais ou menos & 03 & 7.1 \\
\hline TOTAL & 42 & 100 \\
\hline
\end{tabular}

Fonte: Entrevistas crianças/dados primários

É possível perceber um incentivo à frequência à escola, mas não se trata de uma exigência que possa alijar a criança de treinos ou de jogos, como apontam as falas a seguir:

Não achamos que seja medida eficaz, qualquer medida de punição nesse sentido não acontece. O que acontece são situações comportamentais, e que a gente tá vendo de que forma a gente vai fazer. Porque os que tem salário tem uma caixinha ${ }^{19}$, que a gente chama, os que não se comportam na escola, eles tem uma caixinha que eles tem que pagar ou eles ficam sem fazer o passeio, os do alojamento, né. Mas é cobrado sim o desempenho, mas pra ficar nas categorias de base, ser integrantes. É exigido inclusive pelo conselho tutelar, né.(Psicóloga do clube)

Tem, tem o contato direto. Quem faz aqui é a Patrícia né, então o desenvolvimento deles no colégio, ele é diretamente ligado ao que acontece no campo, claro, eu acho que se ele bagunçou naquela semana, mas tá desenvolvendo um futebol muito bom, cabe ao treinador decidir se vai ou não né, isso é um princípio pra cada categoria, cada treinador que toma esse tipo de decisão, eu já vejo que é uma proposta muito grande pra mim.(Auxiliar Técnico)

Outro aspecto que demonstra a centralidade do futebol na vida das crianças é o fato de que, quando indagados sobre a importância da escola nas suas vidas, suas respostas apontam para a relação entre a escola e a aprendizagem com o futebol:

20 Trata-se de um pagamento em dinheiro em restituição a algum ato de descomprometimento com o time e com os colegas, como atraso a treinos, problemas na escola etc. 
Tabela 17- O que aprende na escola é importante para a carreira de jogador de futebol?

\begin{tabular}{|c|c|c|}
\hline RESPOSTAS & $\mathbf{N}^{\mathbf{0}}$ RESPOSTAS & FREQUÊNCIA \% \\
\hline Sim & 41 & 100 \\
\hline Não & 00 & 00 \\
\hline TOTAL & 41 & 100 \\
\hline
\end{tabular}

Fonte: Entrevistas crianças/dados primários

Interessante observar que as crianças já incorporam desde cedo alguns aspectos associados ao habitus de jogador de futebol aometié de atleta do futebol:

Tabela 18- Como a escola auxilia na carreira de jogador de futebol?

\begin{tabular}{|c|c|c|}
\hline RESPOSTAS & $\mathbf{N}^{\mathbf{0}}$ RESPOSTAS & FREQUÊNCIA \% \\
\hline Para saber conceder entrevistas & 24 & 28.9 \\
\hline Para saber lidar com o dinheiro/números & 16 & 19.3 \\
\hline Para aprender outras línguas & 12 & 14.4 \\
\hline Para ser educado e disciplinado & 10 & 12 \\
\hline Para ser esperto/inteligente & 07 & 8.4 \\
\hline Ensina a se relacionar & 04 & 4.8 \\
\hline A ser humilde & 02 & 2.4 \\
\hline A ter raciocínio rápido, dentro de campo & 02 & 2.4 \\
\hline Poder ter outra profissão se não for jogador & 02 & 2.4 \\
\hline Para conhecer outras culturas do país e exterior & 01 & 1.2 \\
\hline É uma exigência do clube & 01 & 1.2 \\
\hline A não pensar só em dinheiro & 01 & 1.2 \\
\hline Saber sobre o corpo & 01 & 1.2 \\
\hline TOTAL & 83 & 100 \\
\hline
\end{tabular}

Fonte: Entrevistas crianças/dados primários

Reiteramos a centralidade do futebol na vida das crianças e de seus familiares e o fato de que a escola é colocada em segundo plano na relação com o investimento com vistas à profissionalização.

Categorias de base de futebol: espaço de instauração de competências

Todas as práticas sociais são formativas e instauram saberes, formação que não necessariamente está ligada à experiência na escola, educação formal somente. 
Nesse sentido, mesmo uma atividade árdua como o trabalho infantil forma e instaura determinadas competências.

Nossa pesquisa avaliou também a instauração de determinadas competências através dessa experiência no clube:

Tabela 19- $O$ que ele mais aprende neste convívio?

\begin{tabular}{|c|c|c|}
\hline RESPOSTAS* & $\mathbf{N}^{\mathbf{0}}$ RESPOSTAS & $\mathbf{\%}$ \\
\hline A ser responsável & 39 & 13.8 \\
\hline A respeitar a hierarquia & 38 & 13.5 \\
\hline A trabalhar em equipe & 37 & 13.1 \\
\hline A lidar com a pressão & 36 & 12.8 \\
\hline Afasta das drogas e da marginalidade & 35 & 12.4 \\
\hline A conviver com as dificuldades & 35 & 12.4 \\
\hline A organizar-se melhor/ser disciplinado & 36 & 12.8 \\
\hline A conviver com as diferenças e com os diferentes & 07 & 2.5 \\
\hline A buscar seus sonhos e lutar pelo que deseja & 02 & 0.7 \\
\hline A ser: educado/respeitoso/cidadão & 03 & 1 \\
\hline A aceitar a derrota/ter autocrítica & 02 & 0.7 \\
\hline A ser flexível & 01 & 0.3 \\
\hline A não ficar ocioso & 01 & 0.3 \\
\hline Ele amadureceu & 03 & 1 \\
\hline Amizade / carisma & 03 & 1 \\
\hline Experiência & 01 & 0.3 \\
\hline Superação & 02 & 0.7 \\
\hline TOTAL & 01 & 0.3 \\
\hline Não dar atença comentários & 282 & 99.6 \\
\hline
\end{tabular}

Fonte: Entrevistas pais/responsáveis *Alguns pais deram mais que uma resposta

As falas a seguir reiteram os saberes instaurados nesse processo:

Ah, respeito, disciplina, colaboração, cooperação, não sei como é que tu quer colocar, porque tudo é em equipe, né. Eles aprendem que eles não são únicos, que a equipe depende deles, mas que a equipe só vai funcionar se todos estiverem integrados. (Auxiliar técnico)

A instauração de determinadas competências aplica-se também à formação demandada ao jogador de futebol profissional, atribuição e missão das categorias de base dos clubes de futebol. É claro que saber jogar futebol é condição para o ingresso nesse espaço de formação, espaço cobiçado e muitíssimo disputado. Porém, refere-se aqui, por exemplo, a importância da postura deste futuro profissional dentro e fora dos gramados, diante de um mundo caracterizado pela visibilidade e pela interconexão, um 
"Mundo Plano". ${ }^{20}$ Ao jogador de futebol é demandado um conjunto de novas habilidades que extrapolam apenas saber jogar futebol. Ser atleta é uma dessas demandas, assim como preservar sua imagem e estar atento com os atos fora do campo, tendo em vista serem futuros homens públicos.

A gente diz pra eles, é imprescindível pra vocês estarem bem dentro de campo que os setores da vida de vocês estejam bem, o colégio, a família, vocês com os colegas de quarto, com a comissão técnica, então são vários aspectos juntos que tu tem que te defrontar porque o clube é muito grande. (Psicóloga do clube)

É um conjunto de coisas, então ele tem que ter disciplina, tática, tem que ser um guri inteligente, primordialmente acho que a inteligência faz a diferença, de um bom jogador, a um jogador comum, acho que é a inteligência pra jogar e a educação dele, porque é muito importante hoje em dia uni a parte física à inteligência. (auxiliar técnico).

Formar eles como homens, né, passar os valores de indivíduo, que eu acho isso mais importante, e depois sim, formar atletas para o clube. Honestidade, cidadania, eles tem que aprender a ter coleguismo, colaboração entre eles. Acho que são assim mesmo, são as coisas primordiais que nós temos que incentivar dentro da formação deles. (auxiliar técnico)

Esses códigos de conduta já estão presentes desde cedo nesse contexto de formação de atletas.

É eu passei por isso, e tipo eu não tinha amigos no colégio né, isso aí foi um dado ruim, quando tu teve a viagem no colégio no fim de semana... missões...Eu nunca fui, geralmente eu tinha jogo, tinha que ficar aqui e tal, mas por outro lado ganhei respeito, disciplina, questão de horário, cumprimento de horário, isso aí, questão de amigos dentro do futebol também, que eu tenho até hoje. (Preparador físico)

É , eu acho que é os principais pontos né, se ele der trabalho e não virar jogador ele vai virar um bom cidadão como a gente chama, chamaria né, então a disciplina, o respeito né, o comprometimento, questão de horário, deles cumprirem horário, isso aí tudo que eu acho que é o principal. (Auxiliar técnico)

Rapidamente podemos apontar para a importância de uma formação integral demandada para: o trato do jogador com seu empresário; o conhecimento sobre seus direitos e deveres na relação trabalhista que estabelece com o clube que o emprega, bem como na sua relação com seus representantes e patrocinadores; o contato com a imprensa e um mínimo entendimento da lógica de funcionamento e dos interesses da 
imprensa de uma maneira geral; da própria questão cultural embutida nas decisões e tomadas de decisões de dirigentes e torcedores (como no caso específico do Rio Grande do Sul, a rivalidade GRE-NAL). Além disso, podemos apontar também para o cuidado com sua imagem pública, fora do campo, que é fundamental e determinante para seu sucesso, sobretudo hoje frente à visibilidade, à velocidade e ao compartilhamento que caracterizam a Sociedade em Rede, para ficarmos apenas com alguns poucos exemplos. Vê-se que a experiências das crianças e adolescentes nesse espaço de formação, que são as categorias de base de futebol, instaura também saberes, realidade que não pode ser ignorada, sob o risco de que a pesquisa não dê conta da complexidade que constitui o fenômeno analisado.

\section{Considerações Finais}

O que se procurou demonstrar neste artigo, longe de lançar um olhar denuncista e alarmistasobre essa modalidade peculiar de trabalho infantil, é como se complexificou o processo de formação de crianças através do futebol, mais especificamente nas escolas de formação de futebolistas profissionais como as categorias de base do Internacional.

O ingresso da criança e do adolescente no universo competitivo das categorias de base dos clubes de futebol profissional não obstante representar uma possibilidade real, porém remota de materialização de um sonho infantil e de ascensão social da criança e de sua família, exige dela uma série de interações, que por vezes não são condizentes com sua idade cronológica, tanto mental como fisicamente, pelo menos na comparação com outras crianças que, nessa faixa etária, têm a possibilidade de experimentar outros tipos de interações.

Exige-se a antecipação de etapas no desenvolvimento dos atletas para dar conta das demandas desse subcampo (futebol) hoje. Observa-se uma inversão de papéis entre pais e crianças, pois é depositada toda uma expectativa no sucesso da criança no futebol profissional, o que explica o porquê do investimento feito pela família. Porém, a intensidade das relações demandas por esse campo que, como todos os campos que compõem o espaço social é construído através de disputas (interativas e/ou conflitivas), instaura também um conjunto de saberes, sobretudo se levarmos em conta a realidade desses agentes e os espaços de formação a que têm acesso. 
Embora constitua-se em uma possibilidade remota, porém real de mobilidade social, o universo que envolve o mundo do futebol incide sobre a qualidade da infância dessas crianças de uma maneira geral, sobretudo à luz dos avanços legais e conceituais que envolvem o imaginário da infância no Brasil. Não obstante todas as características e exigências demandadas ao atleta profissional, e mais especificamente ao atleta de um esporte competitivo e popular como o futebol, é possível humanizar esse espaço de formação. Não se trata de desconhecer a dinâmica que caracteriza o campo esportivo de alto desempenho, nem de abordar de maneira ingênua a forma talvez necessariamente rude como são forjados os "vencedores", aqueles que se tornam profissionais por exemploe que resistem às provações e pressões que envolvem esse contexto, cuja competitividade agora se dá em escala global. Mas trata-se, sim, de levar em conta em que medida as disputas que caracterizam as relações dentro dos campos podem ser construídas de uma maneira mais interativa e menos conflitiva e com maior esclarecimento,principalmente aos pais e responsáveis pelas crianças, sobre as pequenas probabilidades de sucesso nesse projeto.

É nesse contexto que há hoje a possibilidade concreta de aprimorar essa escola de formação que são os clubes de futebol, através da realização de pesquisas (diagnósticos) e de projetos de intervenção junto a esses agentes. A pesquisa, ao realizar um diagnóstico desta realidade e desta demanda social emergente, pode subsidiar projetos voltados às famílias de atletas, a funcionários dos clubes e, claro, às próprias crianças e adolescentes envolvidos nesta realidade, trazendo os riscos que envolvem esse investimento pela busca do sonho de se tornar atleta de futebol profissional.

\section{Referências}

ALMEIDA NETO, Honor de. Trabalho Infantil na Terceira Revolução Industrial. Porto Alegre: EDIPUCRS, 2007. E-book: http://www.pucrs.br/edipucrs. 244 p.

ASSMANN, Hugo: JUNG, MoSung. Competência e Sensibilidade Solidária: educar para a esperança. Petrópolis, RJ: Editora Vozes, 2000.

BAUMAN, Zygmunt. Modernidade líquida. R.J.: Ed. Zahar, 2001.

BOURDIEU, Pierre. Coisas ditas. São Paulo: Brasiliense, 1990. 233p.

. Razões práticas: sobre a teoria da ação. São Paulo: Papirus, 1997a. 231p. 
. O poder simbólico. Lisboa: DIFEL, 1989.

BRASIL.Estatuto da Criança e do Adolescente. Lei Federal 8.069/1990. Porto Alegre: CMDCA (Conselho Municipal dos Direitos das Crianças e dos Adolescentes), dez. 1997. 136p.

CASTELLS, Manuel. A sociedade em rede - A era da informação: economia, sociedade e cultura. São Paulo: Paz e Terra, 1999. 617 págs.

A Galáxia da Internet- reflexões sobre a Internet, os negócios e a Sociedade. Rio de Janeiro: Jorge Zahar, 2003.

DAMO, ArleiSander. Do dom à profissão: a formação de futebolistas no Brasil e na França. São Paulo: HUCITEC, 2007.

DESAULNIERS, Julieta Beatriz Ramos. Formação e pesquisa: condições e resultados. Veritas, Porto Alegre, Edipucrs, v.42, n. 2, p.183-204, jun. 1997.

ELKIND, David. Sem Tempo de ser Criança: a Infância Estressada. Porto Alegre: Editora Artmed, 2004.

FRIEDMAN, Thomas L. O Mundo é Plano: uma breve história do século XXI. Rio de Janeiro: Ed. Objetiva, 2005.

FURTADO, Bernardino. Jogo sujo na mira. Disponível em http://brasilcontraapedofilia.0freehosting.com/2008/02/21/jogo-sujo-na-mira/. Capturado em 16 de setembro de 2008.

MORIN, Edgar; KERN, Anne Brigitte. Terra pátria. Porto Alegre: Sulina, 2000. . Os sete saberes necessários à educação do futuro. São Paulo: Cortez/Brasília, DF:

UNESCO, 2000.

O QUE É TRABALHO INFANTIL. Rede Peteca. Disponível em http://www.chegadetrabalhoinfantil.org.br/trabalho-infantil/conceito. Capturado em 05/06/2018. PERSONNE, Jacques. Nenhuma medalha vale a saúde de uma criança. Lisboa: Livros Horizonte, 2001.

POSTMAN, Neil. O desaparecimento da Infância. Rio de Janeiro: Graphia, 1999.

Recebido 09 de setembro 2018

Aprovado 15 de dezembro 2018 